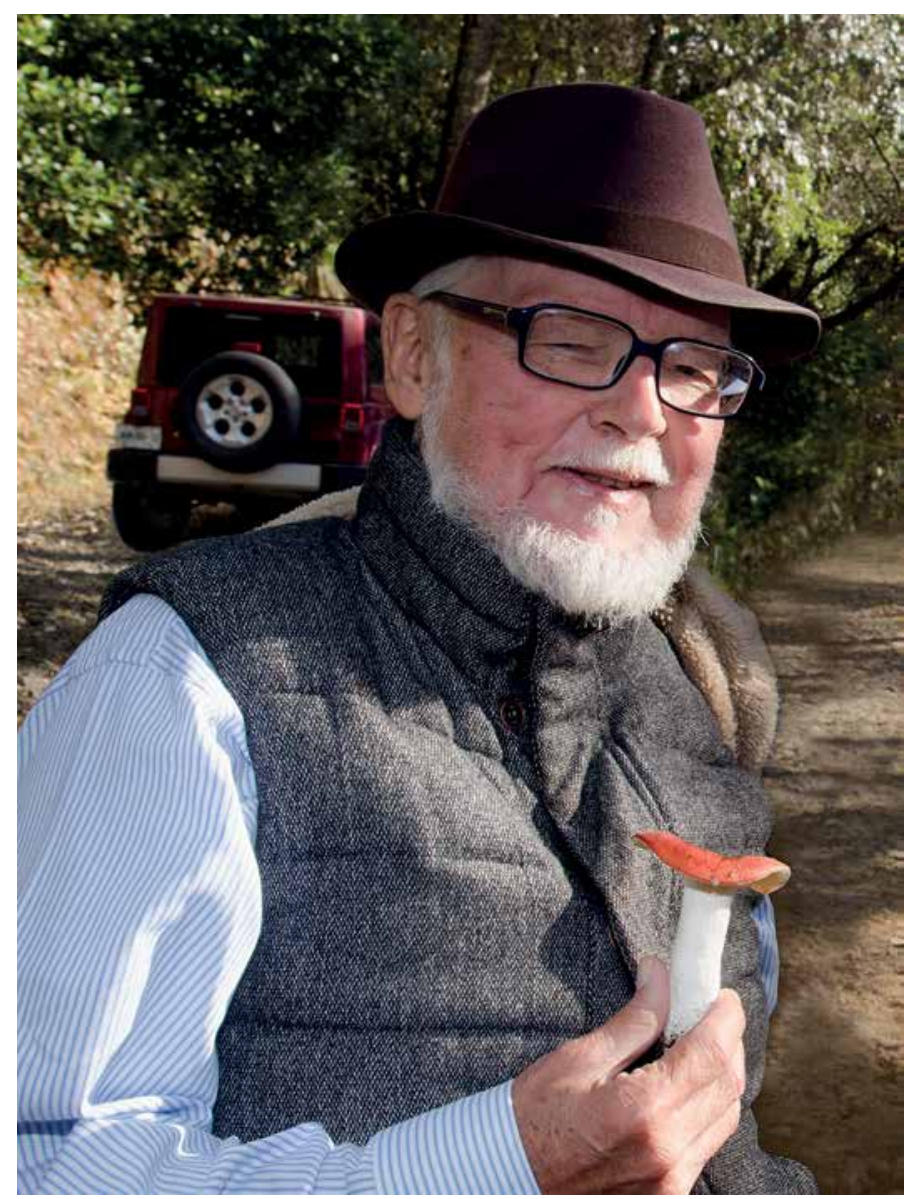

\title{
GASTÓN GUZMÁN (1932-2016)
}

Gastón Guzmán Huerta nació en la ciudad de Xalapa el 26 de agosto de 1932, no obstante que su familia vivía en Tampico. Sus padres fueron Luis P. Guzmán y Concepción Huerta y fue el tercero de cuatro hermanos. Cuando tenía alrededor de dos años se presentó una fuerte inundación en Tampico -su papá entraba en lancha en su casa- y Gastón estaba muy enfermo, por lo que toda la familia se trasladó a la Ciudad de México. Posteriormente, se mudaron a Xalapa cuando Gastón tenía 10 años y vivieron ahí hasta que cumplió quince. "Toco", apelativo con el que su familia lo llamaba de cariño, tuvo de niño una curiosidad natural por los seres vivos, que se vio incrementada al habitar fuera de la ciudad, en el Rancho de Lucas Martín, 
cerca de Xalapa. Fue en la preparatoria el momento en que ese interés fue dirigido por su querida profesora de Zoología, la maestra Enriqueta Ortega, quién lo motivó para que iniciara sus estudios de Biología en la Escuela Nacional de Ciencias Biológicas (ENCB), del Instituto Politécnico Nacional. Esta institución lo formó, primero como Licenciado en Biología (1959) y después como Doctor en Ciencias (1967) y en ella laboró como profesor e investigador por casi 30 años, de 1956 a 1982.

Su primer hongo lo recolectó en 1951 en Necaxa, Puebla, en una excursión estudiantil. En 1955, el joven Gastón Guzmán, de 23 años, emprendió formalmente el estudio de estos organismos. Fue una feliz coincidencia que en la época en que Guzmán se inició como micólogo, los hongos alucinógenos fueron redescubiertos a la ciencia por Gordon Wasson, quien después llegaría a ser considerado el fundador de la etnomicología. El primer micólogo que conoció Guzmán fue el Dr. Teófilo Herrera en 1956, quien era el único especialista de macromicetes en México por aquel entonces. De ahí nació una fructífera y muy buena amistad, con el común denominador de los hongos.

En 1956-1957 la empresa farmacéutica Geigy de Suiza encargó a Guzmán recolectar hongos alucinógenos, de los cuales apenas empezaba a tener nociones. A tal grado que como él mismo reconocía, no sabía si alucinógenos se escribía con "h" o sin ella, confundido porque en inglés se usa con " $h$ " y en español no. Previamente, en 1953 Syntex y en 1954 Pfizer lo contrataron para buscar barbasco (Dioscorea spp.), la primera compañía en México y la segunda en las selvas de América Central. En 1957, gracias a que Teófilo Herrera lo contacta, sale en una expedición de dos meses con el ilustre micólogo Rolf Singer a las montañas Mazatecas, en la búsqueda de los hongos alucinógenos. Singer fue el maestro que dio el empuje micológico formal e inicial a Guzmán. Fue en este viaje cuando tuvo la fortuna de convivir con Wasson. Un poco más tarde conoció Roger Heim y fueron precisamente los artículos del mismo sobre los hongos alucinógenos, los primeros que leyó Guzmán antes de iniciar sus excursiones en búsqueda de ellos. Después de estas experiencias, fue algo natural que los primeros artículos y la tesis profesional de Guzmán versaran sobre este tema. Su tesis de licenciatura la tituló "Estudio taxonómico y ecológico de los hongos neurotrópicos mexicanos" y se la dedicó a Singer, Heim, Herrera y Wasson.

En 1965 hizo una estancia predoctoral en la Universidad de Michigan, becado por la ENCB, la OEA y la Universidad de Michigan, en donde inició su tesis doctoral bajo la dirección de los doctores Alexander H. Smith de EUA y Jerzy Rzedowski de México, sobre una monografía mundial del género Scleroderma, que defendió en la ENCB en 1967 y que se publicó en 1970 en la revista Darwiniana. Estableció contacto, primero por carta y luego personal, con Richard Evans Schultes, el padre 
de la etnobotánica y el primero en determinar al Teonanácatl como un hongo, en una publicación de 1939. Gracias a Schultes, Guzmán obtuvo la beca de la Guggenheim Memorial Foundation de Nueva York en 1971, que le permitió estudiar Psilocybe por todo el mundo y tener como resultado final la monografía de este género, publicada por la editorial Koeltz en 1983. Posteriormente, en 1995 dio a conocer un suplemento de la monografía y numerosos artículos sobre Psilocybe, los que lo convirtieron en la autoridad mundial del género.

Formó en 1955 la Colección de Hongos del Herbario ENCB, actualmente la más grande de México, con más de 90000 especímenes. Posteriormente, en 1982 fue invitado a trabajar en el Instituto Nacional de Investigaciones sobre Recursos Bióticos en Xalapa, en donde desarrolló la segunda colección micológica de mayor tamaño en el Herbario XAL, con más de 55000 ejemplares, incorporada ahora al Instituto de Ecología, al cerrar la primera institución. Guzmán continuó recolectando hongos toda su vida y el último, que corresponde a su número de registro 41115 fue una Russula en el volcán de Tequila, Jalisco, el primer día de 2016.

Sin temor a equivocarme, el libro de hongos más utilizado en México y en muchas partes de América Latina es "Identificación de los Hongos" que publicó la editorial Limusa en 1977, con varias reimpresiones y que Guzmán realizó a partir de sus apuntes para determinar estos organismos y que utilizaba en la cátedra de Micología que él inició. Este libro fue la primera guía de hongos en México y en América Latina. Publicó más de 420 trabajos, entre artículos en más de 300 revistas arbitradas, más de 40 capítulos de libros y 14 libros. Describió tres géneros nuevos, más de 220 especies y 15 variedades nuevas para la ciencia, además realizó numerosas combinaciones y enmendaciones. Siempre trabajó a paso acelerado y quería que todos lo hiciéramos así, pero realmente era muy difícil seguirle el ritmo. Dejó varios manuscritos en proceso y muchos proyectos por desarrollar.

Guzmán fue un organizador nato, así que organizó laboratorios, colecciones, sociedades, exposiciones, seminarios, simposis, entre otros. Formó el Laboratorio de Micología y la colección de hongos en ENCB, a la que le siguió la de XAL, las cuales son las más grandes de México. Fundó la Sociedad Mexicana de Micología en 1968 junto con el Dr. Herrera, en la que Guzmán fue editor de su revista por 20 años. Tuvo también la iniciativa para que se creara la Asociación Latinoamericana de Micología, de la que fue Presidente de 1999 a 2002 y organizó el V Congreso Latinoamericano de Micología en Xalapa. Inició con las exposiciones de hongos en la Ciudad de México, a la que le siguieron alrededor de 100 en varias partes de la República, así como en Guatemala y Panamá. Formó más de 25 especialistas en esta materia, no solo en México, sino también Guatemala y Colombia. 
Contrajo matrimonio en mayo de 1960 con Laura Dávalos Sánchez y tuvieron cuatro hijos. En febrero de 1961 nace la primogénita, Laura, en agosto de 1963 su segundo hijo, Gastón, quien falleció en un trágico accidente a los 15 años. En octubre de 1964 nace Gaby, la tercera, y finalmente, Vero en febrero de 1970. Él regresa a Xalapa en 1982 y se vuelve a casar en 1995 con Isabel Lasserre Bonilla. Su vida personal fue, como la académica, muy fructífera, le encantaba la música romántica de antaño, la bohemia e incluso escribió algunos poemas. Guapo, carismático y enamoradizo, un imán para muchas.

Al hablar de hongos mexicanos, de hongos alucinógenos y de etnomicología, inmediatamente viene a la mente el Dr. Guzmán. Desafortunadamente no podía ser eterno, por más que yo y muchos lo hayamos querido, y falleció el 12 de enero de 2016. Trabajó casi hasta el último momento -revisó un proyecto de tesis en el hospital una semana antes de fallecer-, incansable como siempre. Fue un investigador muy activo, comprometido, productivo, profesional, líder; como profesor muy bueno enseñando, ameno, pero muy estricto y exigente, en ocasiones poco paciente y muy regañón. Como persona vivió intensamente, fue muy sociable y fácilmente se convertía en el centro de atención. Estoy segura que en muchas personas nos dejó una huella imborrable, en algunos de "dinosaurio" como Ruth De León, discípula guatemalteca, quien me lo escribió, y sus trabajos siempre serán referente en la micología, sobre todo en la nacional y latinoamericana. Tuvimos el privilegio de tenerlo entre nosotros, hoy está en nosotros, en nuestros artículos, en nuestras citas, en nuestra biblioteca, en nuestros recuerdos, en nuestro corazón. Gracias Dr. Guzmán.

Laura Guzmán Dávalos Universidad de Guadalajara 